\title{
Reseña de la Exposición La violencia en el espacio. Políticas urbanas y territoriales durante la dictadura cívico-militar en Argentina (1976-1983), Rosario, 2018
}

\author{
JULIETA CITRONI (CESIL / FHUC - UNL) \\ Centro de Estudios Sociales Interdisciplinarios del Litoral \\ Facultad de Humanidades y Ciencias \\ Universidad Nacional del Litoral \\ Santa Fe, Argentina \\ julietacitroni@gmail.com
}

Recibido: 08/11/2019 - Aceptado: 05/12/2019

Habilitada el 6 de septiembre de 2018 en Rosario, La violencia en el espacio. Politicas urbanas y territoriales durante la dictadura cívico-militar en Argentina (1976-1983) se mantuvo abierta durante todo el mes. El lugar elegido fue el Centro Cultural Roberto Fontanarrosa, de gestión municipal, dilatada trayectoria y ubicación céntrica. Luego, en 2019, la exposición se trasladó al Centro Cultural de la Memoria Haroldo Conti, dentro del predio de la ex ESMA que hoy depende de la Secretaría de Derechos Humanos de la Nación, en los bordes de la Capital Federal. Allí estuvo exhibida durante casi dos meses $-\mathrm{y}$ rondando una fecha clave para la memoria-, del 23 de marzo al 19 de mayo. La última de las instalaciones fue en el corazón del conurbano bonaerense, en el Multiespacio Cultural de la "joven” Universidad Nacional de General Sarmiento, donde más tiempo estuvo disponible: desde el 11 de junio al 6 de septiembre pasado. Siempre sostuvo la premisa del acceso libre y gratuito y la posibilidad de recorrerla de manera autónoma.

El día de la inauguración oficial, Pamela Colombo y Carlos Salamanca, en tanto coordinadores generales de la muestra, oficiaron de anfitriones. En el caso de las distintas sedes que recorrió, las aperturas estuvieron a cargo de algunos de los que produjeron el material para la misma, como parte de sus investigaciones en curso. Se trata de un nutrido colectivo de docentes, doctorandos e investigadores de mediana edad con cierto prestigio en el medio académico y, más precisamente, de las políticas urbanas de la última dictadura. El antecedente de la propuesta fue la participación de buena parte de ellos en un dosier más amplio -marcado por la perspectiva latinoamericana- de la reconocida revista Clepsidra, que fue desdoblado en dos números consecutivos, en función del volumen y la orientación de los artículos recibidos. ${ }^{1}$

Para la exposición, se incorporaron realizadores audiovisuales, fotógrafos y museógrafos, al tiempo que la extensa lista de agradecimientos incluye la colaboración desinteresada de los responsables de archivos públicos y privados de distintos puntos del país, para recopilar el abundante material visual. Precisamente, ahí reside una de sus fortalezas: apoyándose en una gran cantidad de fotografías, noticias periodísticas, tiras cómicas, algunas filmaciones del período, junto a dibujos que ilustran ciertas palabras clave, construye un relato novedoso. En primer lugar, por tratarse de una exhibición accesible e itinerante, un formato poco explorado por la academia argentina para divulgar masivamente su producción intelectual. Pero, además, como afirman los coordinadores en el texto curatorial impreso en el folleto que la acompaña,

\footnotetext{
1 Clepsidra. Revista Interdisciplinaria de estudios sobre memoria, dosieres "Regímenes autoritarios, nuevas geografías y espacios de vida en América Latina”, núm. 9 y "Erradicación de villas, resistencia popular y regímenes autoritarios en América Latina”, núm. 10. Ambos coordinados por Colombo y Salamanca, corresponden al volumen 5 del año 2018, en línea en: http://ppct.caicyt.gov.ar/index.php/clepsidra/issue/archive, consulta: 1 de noviembre de 2019.
} 
"Esta exposición explora una forma de gobierno en la que la violencia fue un elemento constitutivo y donde, al mismo tiempo que se diseñaban los circuitos del terror y que los espacios de vida eran objeto de vigilancia permanente, se organizaban ferias infantiles, mundiales de fútbol, la ‘buena gestión' de la basura, el patrimonio cultural o el turismo."”

Este enfoque preocupado por señalar aquello de productivo y modernizador que tuvo el gobierno de facto instituido en Argentina el 24 de marzo de 1976, especialmente en las zonas urbanas, forma parte de los últimos desarrollos del ámbito investigativo. Y, por lo mismo, no ha calado lo suficiente en el gran público -a quien se dirige la propuesta- de la manera que lo ha hecho su faz represiva, plenamente instalada en el imaginario. Sin embargo, es posible reconocer esta "contracara" al transitar por rutas y calles argentinas, indagando en la historia de ciertos hitos urbanos autoritarios. Entre ellos se cuentan, el rediseño de espacios públicos, la construcción de autopistas y conjuntos habitacionales, la readecuación de estadios y la creación de parques nacionales y pueblos estratégicos en zonas fronterizas. Al observar la huella que han dejado en el presente -en sectores sociales y espaciales marginales y, por consiguiente, en otros revalorizadosse puede entrever la idea de ciudad (y sociedad) que subyacía detrás: la constante es la exclusión.

Desde la realización de grandes proyectos urbanos, territoriales e infraestructurales hasta el rediseño de mapas, la re-nominación de pueblos, la revisión de efemérides o la reeducación moral de la población, se trata de una serie de emprendimientos que "permite pensar ese 'mundo nuevo' en el que, a través de la violencia, el espacio se utilizó como un medio para 'crear', 'civilizar', 'domesticar', 'enseñar', 'sanar'...”. ${ }^{3}$ Es ahí adonde apunta la exhibición, a aguzar la vista en esa dirección. Para ello, despliega la información en cinco secciones secuenciales, caracterizadas por marcas distintivas, que ya se advierten en los títulos: Diseño y construcción a gran escala, Espacios de expulsión, Espacios de vida, Espacios de esparcimiento, Ecologismo y naturaleza.

Las conforman paneles explicativos impresos a color -compuestos por fotografías y textos, en ocasiones algo extensos- y dispuestos en simples estructuras construidas en madera liviana y armadas como si fueran recintos a los que se debe ingresar para conocer su contenido. También hay algunos videos de la época que se proyectan continuamente, dentro de pequeñas pantallas enmarcadas en cartón corrugado. Se trata de materiales reciclados, de bajo costo, cotidianos, al alcance de todos, como el tema de la muestra. Lo que más llama la atención en la presentación rosarina, es un gran plano del ejido urbano actual desplegado sobre una mesa baja, para la intervención de los visitantes, con notas post-it, fibrones y piolines a disposición. Será para el momento en que, quien se sienta interpelado, deje plasmados sus recuerdos de las "marcas de la dictadura" en la ciudad (destacadas o anónimas, comprobadas o imposibles de verificar hoy). Es una apuesta que surte efecto y abona la construcción colectiva del conocimiento sobre lo social.

Justamente, los lugares elegidos para el emplazamiento de la exposición durante su itinerancia, no fueron casuales o ingenuos. El Centro Cultural Roberto Fontanarrosa tiene su origen en el año 1978, luego de la demolición de un viejo mercado abastecedor de productos frescos en plena zona céntrica, durante la década anterior. Fue erigido como Centro de Prensa correspondiente a la subsede Rosario del Mundial '78 y, al finalizar el torneo, inmediatamente transferido a la municipalidad para su transformación en lo que es hoy. Por su parte, la historia de la Escuela de Mecánica de la Armada es más conocida, puesto que allí funcionó uno de los mayores centros clandestinos de detención, tortura y extermino del régimen. Allí, el activo equipo de diseño de "El Conti" modificó la primera versión, así como la UNGS propuso especialmente "una cartografía

\footnotetext{
2 Parte del mismo se encuentra transcripto en el sitio web de la exposición, habilitado en marzo de 2019, en formato blog. "Texto curatorial", en Exposición: La violencia en el espacio. Políticas urbanas y territoriales durante la dictadura cívicomilitar en Argentina (1976-1983), en línea en: https://violenciaesp.hypotheses.org/category/presentacion-de-laexposicion, consulta: 1 de noviembre de 2019.

3 "Texto curatorial", en Exposición: La violencia en el espacio..., en línea en: https://violenciaesp.hypotheses.org/category/presentacion-de-la-exposicion, consulta: 1 de noviembre de 2019.
} 
de experiencias del noroeste del conurbano", en palabras del profesor de la casa que colaboró en el proyecto y guió la primera visita. ${ }^{4}$

En este sentido, se podría especular con que el recorrido fue desde el centro (de una ciudad) hacia las periferias, así como aquellas acciones de limpieza de la metrópoli porteña que expulsaban poblaciones, viviendas, transportes, mercados y residuos hacia sus límites. El mismo patrón se repite en todas las grandes y medianas urbes cercadas por avenidas de circunvalación, un proyecto muy en boga entonces. No obstante, cabría hacer otra lectura de aquel derrotero y recalcar que la apertura se haya hecho en "el interior" (del país) y de allí haya viajado a la Capital Federal. Esto se explica porque uno de los organismos que respaldaron el emprendimiento fue la Universidad Nacional de Rosario, lugar de trabajo del investigador del CONICET colombiano, Carlos Salamanca. Mientras que el otro apoyo económico provino de la Ecole des Hautes Etudes en Sciences Sociales, adonde se encuentra radicada su colega argentina, Pamela Colombo.

A esta clave de trabajo conjunto y colaborativo entre instituciones, se suma el abordaje interdisciplinario de la muestra que, a su vez, continúa la línea de los estudios urbanos sobre la dictadura. En ella convergen historiadores, sociólogos, antropólogos, arquitectos, urbanistas y ecólogos, entre otras ciencias sociales, en un diálogo fructífero. Convocados para la exposición por las vías académicas habituales, estos profesionales proceden, además de las universidades mencionadas, en su mayoría de la UBA. A partir de sus investigaciones se logra cubrir buena parte del mapa nacional, si bien se detecta que algunas localidades no han sido consideradas en su especificidad -los casos más destacados serían los de Córdoba y Mendoza-, así como tampoco las particularidades del sur del país, reconociendo las exploraciones más incipientes o aisladas que allí se están desarrollando. Lo que no obsta para concluir acertadamente que

"El gobierno militar no desplegó su poder de manera uniforme en todas las regiones o en todas las ciudades del país. Hay zonas que concibió como destinadas a ser 'conquistadas', exaltadas o 'domesticadas', mientras que otras podían ser abandonadas o sacrificadas en aras de un objetivo mayor." 5

\footnotetext{
4 Fernández, Leonardo, "La violencia en el espacio", Noticias UNGS, nº 89, junio 2019, en línea en: https://noticiasungs.ungs.edu.ar/?portfolio=la-violencia-en-el-espacio, consulta: 1 de noviembre de 2019.

5 "Sección 2: Espacios de expulsión", en Exposición: La violencia en el espacio..., en línea en: https://violenciaesp.hypotheses.org/category/seccion-2, consulta: 1 de noviembre de 2019.
} 

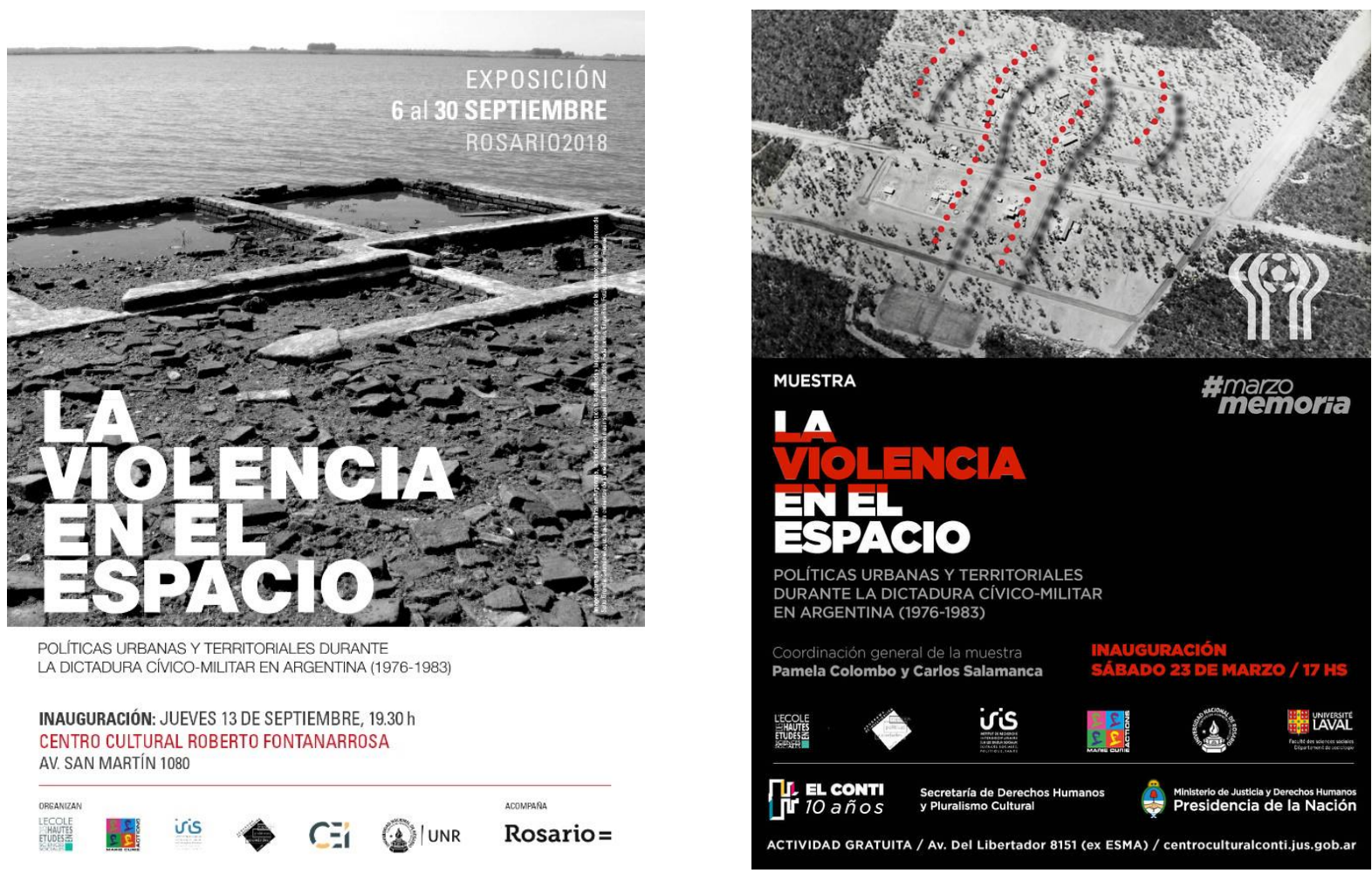

En otro orden de cosas, cabe destacar el esfuerzo de los centros culturales para divulgar la exhibición a través de sus canales habituales, como boletines y revistas particulares. Ejemplo de ello son los flyers que ilustran esta reseña, los cuales evidencian diferencias en las imágenes, la tipografía y, de alguna forma, en el impacto que buscan generar en los destinatarios, aunque se asemejan en la elección de los colores. ${ }^{6}$ Esta tarea también fue promovida por algunas revistas digitales de arquitectura y urbanismo, pero no fue el caso de los grandes medios nacionales, los cuales ni registraron su existencia. La excepción la hicieron algunos portales locales y el suplemento rosarino de Página/12, que entrevistó a los coordinadores en ocasión de la inauguración. ${ }^{7}$ Lamentablemente, el silencio generalizado atenta contra el conocimiento de la temática, que quedaría circunscripta a los círculos habitué de estos lugares, a los cuales no suele concurrir el público masivo.

Por lo mismo, surge la interrogación por el volumen de asistentes que ha recibido la muestra hasta el presente, un dato que no se conoce, pero que sería ineludible que vaya en incremento. Para esto es fundamental que se genere interés en las entidades académicas, culturales y sociales de distintas comunas, a fin de que gestionen su circulación, traslado, instalación y difusión. Si bien el volumen del material podría resultar una cuestión no menor a resolver, de este modo empezará a extenderse la idea de que la sociedad argentina en dictadura no estaba fragmentada en compartimentos estancos o paralelos, que no se trataba de "un gobierno de violencia y otro productivo. Hubo un solo gobierno que inscribió la violencia en el espacio y que hizo del espacio el medio y el lugar para crear de manera autoritaria una nueva sociedad". 8

\footnotetext{
6 Ambos fueron compartidos en Exposición: La violencia en el espacio..., en línea en: https://violenciaesp.hypotheses.org/category/itinerancia, consulta: 8 de noviembre de 2019 .

7 Bastus, Luis, "El 'Nunca Más' de la obra pública", Página/12, Rosario, 23 de septiembre de 2018, en línea en: https://www.pagina12.com.ar/144001-el-nunca-mas-de-la-obra-publica, consulta: 1 de noviembre de 2019.

8 "Texto curatorial", en Exposición: La violencia en el espacio..., en línea en: https://violenciaesp.hypotheses.org/category/presentacion-de-la-exposicion, consulta: 1 de noviembre de 2019.
} 
Mientras se escriben estas líneas, un contacto comparte el anuncio de que en la misma "ciudad de origen" rosarina, se presentará el libro-catálogo que reúne todo el contenido (y el que quedó fuera) de la exposición, con un título abreviado: La violencia en el espacio. Políticas espaciales de la dictadura (1976-1983). Editado por la UNR, sus compiladores y el sitio elegido también se repitieron pero, esta vez, el centenario diario La Capital registró el evento, conversando con Carlos Salamanca. ${ }^{9}$ Ahora cabría preguntarse hacia dónde se dirige la exhibición, luego de un año de itinerancia, ya que el sitio web no lo informa; quizás haya llegado el turno de la institución francesa. Por lo pronto, se puede hacer una primera aproximación navegando por sus entradas o consiguiendo el libro, pero ninguno le hace justicia: todo su esplendor se despliega "en escena", así como la violencia dictatorial.

\footnotetext{
9 "Que aún los jóvenes no puedan habitar ciertos espacios es legado de la dictadura", La Capital, Rosario, 4 de noviembre de 2019, en línea en: https://www.lacapital.com.ar/la-ciudad/que-aun-los-jovenes-no-puedan-habitarciertos-espacios-es-legado-la-dictadura-n2540112.html, consulta: 8 de noviembre de 2019.
} 